OPEN ACCESS

Edited by:

Vasileios Fotopoulos,

Cyprus University of Technology,

Cyprus

Reviewed by:

Costas Delis,

Technological Educational Institute of Peloponnese, Greece

István Molnár,

Centre for Agricultural Research (MTA), Hungary

${ }^{*}$ Correspondence: Archana Singh

sarchana19@gmail.com

Specialty section:

This article was submitted to

Plant Physiology,

a section of the journal

Frontiers in Plant Science

Received: 16 February 2017 Accepted: 19 May 2017

Published: 06 June 2017

Citation:

Samota MK, Sasi M, Awana M

Yadav OP, Amitha Mithra SV,

Tyagi A, Kumar $S$ and Singh A

(2017) Elicitor-Induced Biochemical

and Molecular Manifestations to Improve Drought Tolerance in Rice

(Oryza sativa L.) through

Seed-Priming. Front. Plant Sci. 8:934.

doi: 10.3389/fpls.2017.00934

\section{Elicitor-Induced Biochemical and Molecular Manifestations to Improve Drought Tolerance in Rice (Oryza sativa L.) through Seed-Priming}

\author{
Mahesh K. Samota ${ }^{1}$, Minnu Sasi ${ }^{1}$, Monika Awana ${ }^{1}$, Om P. Yadav ${ }^{1}$, S. V. Amitha Mithra ${ }^{2}$, \\ Aruna Tyagi ${ }^{1}$, Suresh Kumar ${ }^{1}$ and Archana Singh ${ }^{1 *}$
}

${ }^{1}$ Division of Biochemistry, ICAR-Indian Agricultural Research Institute, New Delhi, India, ${ }^{2}$ ICAR-National Research Centre on Plant Biotechnology, New Delhi, India

Rice (Oryza sativa L.) is one of the major grain cereals of the Indian subcontinent which face water-deficit stress for their cultivation. Seed-priming has been reported to be a useful approach to complement stress responses in plants. In the present study, seedpriming with hormonal or chemical elicitor [viz. methyl jasmonate (MJ), salicylic acid (SA), paclobutrazol (PB)] showed significant increase in total phenolic content, antioxidant activity and expression of Rice Drought-responsive (RD1 and RD2) genes (of AP2/ERF family) in contrasting rice genotypes (Nagina-22, drought-tolerant and Pusa Sugandh5, drought-sensitive) under drought stress. However, decrease in lipid peroxidation and protein oxidation was observed not only under the stress but also under control condition in the plants raised from primed seeds. Expression analyses of RD1 and $R D 2$ genes showed upregulated expression in the plants raised from primed seeds under drought stress. Moreover, the RD2 gene and the drought-sensitive genotype showed better response than that of the RD1 gene and the drought-tolerant genotype in combating the effects of drought stress. Among the elicitors, MJ was found to be the most effective for seed-priming, followed by PB and SA. Growth and development of the plants raised from primed seeds were found to be better under control and drought stress conditions compared to that of the plants raised from unprimed seeds under the stress. The present study suggests that seed-priming could be one of the useful approaches to be explored toward the development of simple, cost-effective and farmer-friendly technology to enhance rice yield in rainfed areas.

Keywords: drought responsive gene, drought stress, elicitor, seed-priming, transcription factor

\section{INTRODUCTION}

Rice (Oryza sativa L.) a drought-sensitive crop exhibits impeded growth and development when exposed to water-deficit stress at critical growth stages feeds more than three billion people and provides $50-80 \%$ of the daily calories intake (Khush, 2005). Plants respond to water stress via a series of biochemical, physiological and molecular processes. Evidences suggest that under multiple stresses plants exhibit biochemical and molecular responses in addition to the shared hormonal responses as part of their stress tolerance strategies (Ramegowda and Senthil-Kumar, 2015). In 
many Asian countries, including India rice is generally grown by direct seeding in rainfed areas because it reduces input costs, improves resource use efficiency and improves system productivity (Liu et al., 2015). However, poor germination and stand-establishment of direct-seeded rice under the unfavorable environmental conditions remains a major impediment.

Although development of drought-tolerant crop varieties has been a challenging task, progress has been made in this direction with identification of certain bottlenecks. Therefore, alternative strategies to improve drought tolerance in rice are required to meet the increasing demand of rice when uneven distribution of rainfall and extreme weather conditions are observed frequently due to the climate change. Seed-priming, a controlled hydration technique that induces pre-germination metabolism without allowing radicle emergence, has emerged as a practical and effective approach to enhance tolerance against various abiotic stresses (Jisha et al., 2013; Paparella et al., 2015). Chen et al. (2010) reported that seed-priming enables the seedling to cope with environmental stresses by vigorous head-start or/and cross tolerance. Seed-priming affects biochemical and physiological processes (synthesis of nucleic acids and proteins, DNA repair, antioxidant activity and energy metabolism) leading to higher stress tolerance ability in the seedlings (Varierf et al., 2010; Hasanuzzaman and Fujita, 2011; Hussain et al., 2016b). Seedpriming has been demonstrated to enhance abiotic stresses tolerance, including drought, salinity, chilling and heavy metals, in different plant species (Ashraf and Rauf, 2001; Farooq et al., 2008; Bayat and Sepehri, 2012; Khan et al., 2012; Hussain et al., 2016a). Seed-priming of wheat with salicylic acid (SA) increased moisture content, dry matter yield, antioxidant activity and total chlorophyll content under drought stress (Singh and Usha, 2003), and selenium (Se) priming was reported to enhance drought tolerance in rapeseed by regulating enzymatic and non-enzymatic antioxidant activities (Hasanuzzaman and Fujita, 2011). Recently, seed-priming with selenium (Se) and SA was reported to be more effective in protecting rice plants against chilling stress (Hussain et al., 2016b). Thus, seed-priming with plant hormone and chemical compound is found to be effective in assuaging the damaging effects of abiotic stress in plants. Moreover, the biochemical, physiological and molecular basis of seed-priming to mitigate abiotic stresses in plants is becoming clear day-byday.

Among the classical plant hormones (see Kumar et al., 2016), SA, jasmonic acid (JA), and a chemical compound paclobutrazol $(\mathrm{PB})$ have been utilized as potential elicitors to enhance abiotic stress tolerance in plants (Pill and Gunter, 2001; Afzal et al., 2006; Bayat and Sepehri, 2012; Khan et al., 2013). In plant biology, elicitors are considered to be extrinsic or foreign molecules that act at very low concentrations and induce plant defense responses. They can attach to specific receptor proteins located on plant cell membranes and are highly specific in elicit secondary metabolite production. Methyl jasmonate (MJ), a methyl ester of JA is a naturally produced plant hormone, which has been used to elicit plant's defense response. Exogenous application of $\mathrm{MJ}$ increased antioxidant activity of plants under water stress (Bandurska et al., 2003) and treatment with $\mathrm{MJ}$ enhanced drought tolerance by increasing synthesis of biochemical compounds such as proline, ascorbic acid, soluble sugars and malondialdehyde (Nazarli et al., 2014). Recently, the role of JA as a critical regulator of proteasome degradation in response to abiotic stress in Arabidopsis and rice has been characterized ( $\mathrm{Wu}$ et al., 2015). PB is a member of triazole family which have been characterized as plant protectants because of their capability to improve antioxidant potential in the stressed plants (Manivannan et al., 2007). It inhibits P450 monooxygenase enzyme and ent-kaurene oxidase which is involved in gibberellic acid biosynthesis. SA, being a plant hormone of phenolic nature and irrespective of its important role in biotic stress, mitigates the damaging effects of drought when applied at lower concentration. SA application suppressed production of reactive oxygen species (ROS) and enhanced the activity of superoxide dismutase and catalase in Kentucky Blue grass (Farooq et al., 2008). The synergistic and antagonistic actions of plant hormones with the drought-responsive abscisic acid (ABA) have been referred as signaling crosstalk (Fujita et al., 2006).

Sense of the stress induces signaling network in plant that activates ion channels, kinase cascades, production of ROS, accumulation of hormones such as ABA, ethylene, JA and SA (Pérez-Clemente et al., 2012). Plants produce MJ during drought stress, which in turn stimulates the production of ABA. Drought-inducible genes encoding the key enzymes of ABA biosynthesis pathway, cellular protective enzymes, signaling proteins and transcription factors (TFs) have been identified in Arabidopsis, rice, and other plant species (Zhu, 2002). Rice OsJMT1 and OsSDR genes were found to be involved in $\mathrm{MJ}$ and $\mathrm{ABA}$ biosynthesis, respectively. Thus, plant responses to the stress are mediated via changes in gene expression which result in alteration in transcriptome, proteome and metabolome. Studies have been conducted in different plant species to investigate the underlying mechanism of priming and stress memory (Ramirez et al., 2015; Wang et al., 2015). Recently, physio-biochemical and molecular mechanisms of seed-priming under drought, chilling and submergence stress in rice has been reported (Salah et al., 2015; Hussain et al., 2016a,b) which elaborate the importance of this technique. Still, much more strategic research is needed to combat drought stress in crop plants. ROSinduced protein oxidation may cause site-specific amino acid modifications, fragmentation of polypeptide, aggregation of cross-linked reaction products, altered electric charge, and increased susceptibility of proteins to proteolysis. In this context, plant-tissue contents of malondialdehyde (MDA) and carbonylated proteins are considered as the biochemical markers of lipid peroxidation (LP)/cell membrane damage and protein oxidation (Møller and Kristensen, 2004), respectively. Increased peroxidation (degradation) of lipids and the elevated protein oxidation have been found to be common in plants growing under environmental stresses (Mishra et al., 2011; Sharma et al., 2012). Measurement of protein oxidation on the basis of sulfhydryl group content indicated that increase in antioxidant enzymes (by SA and MJ) helps reducing protein oxidation, and in turn protects the plant from oxidative stress (Kumari et al., 2015). 
Abscisic acid is well-known to regulate stress responses in plants through the expression of stress-responsive genes. BeldaPalazon et al. (2014) demonstrated that ABA controls production of hypusine (an unusual amino acid found in a eukaryotic translation elongation factor, eIF5A) in Arabidopsis thaliana. The hierarchically upstream regulators of the stress-responsive genes, mainly the TFs, directly control the expression of multiple genes by binding to the cis-regulatory elements in their promoter region. Thus, TFs are considered as master regulators of stress responses (Dey et al., 2016). APETALA2/ethylene-responsive element binding factor (AP2/ERF) family is a large group of plant-specific TFs that includes four major subfamilies: (i) AP2, (ii) Related-to-ABI3/VP1 (RAV), (iii) ERF, and (iv) DREB (dehydration-responsive element-binding protein). Many of the stress-inducible AP2, ERF and DREB subfamily members have been isolated and characterized. They can modulate transcription of downstream genes involved in drought tolerance (Mawlong et al., 2014). Regulation of transcription is a common target to modulate gene expression both under abiotic and biotic stresses.

The present study aimed at understanding physiobiochemical and molecular responses of contrasting rice genotypes at vegetative stage of rice plants raised from the seeds primed with either of the elicitors namely $\mathrm{MJ}, \mathrm{PB}$, or SA and grown under water-deficit stress. One of the objectives of the study was to investigate the possible use of the elicitor in mitigating the harmful effects of water-deficit stress, particularly in the drought-sensitive rice genotype.

\section{MATERIALS AND METHODS}

\section{Plant Material}

Mature seeds of two contrasting rice genotypes Nagina22 (N-22, drought-tolerant) and Pusa Sugandha-5 (PS-5, drought-sensitive) were obtained from the Division of Genetics, ICAR-Indian Agricultural Research Institute, New Delhi. Before priming, seeds of the contrasting rice genotypes were surface sterilized using $0.1 \% \mathrm{HgCl}_{2}$ for $4 \mathrm{~min}$ and washed three times with sterilized double-distilled water.

\section{Experimental Details}

In order to examine the role of seed-priming in alleviating the adverse effects of drought stress in rice, different concentrations of elicitor (MJ, $\mathrm{PB}$, and $\mathrm{SA}$ ) were tested in our preliminary study. The seeds were primed with each of the elicitor separately following the procedure described by Pill and Gunter (2001) for PB, Afzal et al. (2006) for MJ, and Khan et al. (2012) for SA. Based on the germination, seedling growth and vigor (fresh biomass), seed-priming with $100 \mu \mathrm{M}$ was found to be most effective for enhancing drought tolerance in rice (Supplementary Figure S1 and Table S1), and this concentration was used in further experiments. The treatments used in the present study were (1) no-priming + no drought stress, (2) no-priming + drought stress, (3) MJ-priming + no stress, (4) MJ-priming + stress treated, (5) PB-priming + no stress, (6) PB-priming + stress treated, (7) SA-priming + no stress and (8) SA-priming
+ stress treated. Three seeds (primed or unprimed) were sown at equal distance in $4 \times 4$ inches pots, and grown in Phytotron facility under controlled conditions $\left(12 \mathrm{~h}\right.$ light, $30^{\circ} \mathrm{C}$ day $/ 25^{\circ} \mathrm{C}$ night, $\left.75 \% \mathrm{RH}\right)$. Seedlings were irrigated with the half-strength Hoagland solution for 42 days, and then drought stress was imposed by withholding irrigation for 4 days while unstressed (control) seedlings were irrigated continuously. The experiment was laid out in completely randomized design with three biological and three technical replications. Shoot tissues from the biological and technical replicates were collected for biochemical and molecular studies.

\section{Estimation of Soil Moisture and Relative Water Contents}

Soil moisture content (SMC) was determined by gravimetric method. Soil samples were collected from the $5 \mathrm{~cm}$ depth of the pots and placed in pre-weighed Petri plates. The weight of the soil was recorded immediately followed by drying at $60^{\circ} \mathrm{C}$ in an oven till constant/dry weight (DW) of the soil was obtained. SMC was calculated using the formula: $\mathrm{SMC}=[$ (weight of wet soil) - (weight of dried soil)]/(weight of dried soil).

Relative water content (RWC) in shoot was measured according to Barr and Weatherley (1962). Fresh leaves were cut at approximately one-third distance from the tip; a $10 \mathrm{~cm}$ piece was excised from the shoot and placed in a pre-weighed Petri-plate covered with a lid followed by taking fresh weight (FW) as soon as possible. The plate was then filled with distilled water, covered with lid and kept at room temperature for $4 \mathrm{~h}$ to achieve fully turgid condition. Turgid weight (TW) was taken, then leaves were blot dried and kept in an oven at $60^{\circ} \mathrm{C}$ for $24 \mathrm{~h}$ or until constant weight was obtained. DW was recorded and RWC was calculated using the formula: RWC $(\%)=[(F W-D W) /(T W-D W)] \times 100$

\section{Estimation of Total Phenolics Content}

Total phenolics content (TPC) in the shoot samples of the contrasting rice genotypes was determined following the procedure described by Singleton et al. (1999). Briefly, $1.0 \mathrm{~g}$ of fresh shoot tissues were ground into fine powder to which $20 \mathrm{~mL}$ Trichloro acetic acid $(0.1 \%)$ was added and the content was centrifuged at $12,000 \mathrm{rpm}$ for $10 \mathrm{~min}$ at room temperature. The supernatant was collected and $0.5 \mathrm{~mL}$ of the aqueous extract was added to $2.5 \mathrm{~mL}$ of $10 \%$ Folin-Ciocalteu reagent (v/v) and $2 \mathrm{~mL}$ of $7.5 \%$ sodium carbonate. The reaction mixture was incubated at $45^{\circ} \mathrm{C}$ for $40 \mathrm{~min}$ and absorbance was recorded at $765 \mathrm{~nm}$. Gallic acid was used as a phenol standard and TPC was expressed as mg of gallic acid equivalents $\mathrm{g}^{-1}$ extract.

\section{Level of Lipid Peroxidation}

Lipid peroxidation was measured in terms of malondialdehyde (MDA) level in shoot tissues following the procedure described by Cakmak and Horst (1991), which is based on thiobarbituric acid reaction. The sample extract was obtained by grinding $1.0 \mathrm{~g}$ fresh tissues in $20 \mathrm{~mL}$ TCA $(0.1 \%)$ solution followed by centrifugation at $12,000 \mathrm{rpm}$ for $10 \mathrm{~min}$. One $\mathrm{mL}$ supernatant was reacted with $4 \mathrm{~mL}$ TCA (20\%) solution containing $0.6 \%$ thiobarbituric acid. The reaction mixture was heated for $30 \mathrm{~min}$ at 
$95^{\circ} \mathrm{C}$, then cooled on ice followed by centrifugation at $12,000 \mathrm{rpm}$ for $10 \mathrm{~min}$. Absorbance of the supernatant was recorded at 532 and $600 \mathrm{~nm}$, and MDA level was calculated using the extinction coefficient of $155 \mathrm{mM}^{-1} \mathrm{~cm}^{-1}$ using the formula: MDA level $(\mathrm{nM})=\Delta \mathrm{A}_{(532 \mathrm{~nm}-600 \mathrm{~nm})} / 1.56 \times 10^{5}$.

\section{Total Antioxidant Activity}

Total antioxidant activity $(\mathrm{AO})$ in the shoot tissue extracts was measured using the stable DPPH radical following the method described by Hatano et al. (1988). Fresh tissues (1.0 g) were ground into fine powder and extracted with $10 \mathrm{~mL}$ ethanol (90\%) by constant shaking at room temperature for $48 \mathrm{~h}$. The extract was centrifuged $13,000 \mathrm{rpm}$ for $10 \mathrm{~min}$ and the supernatant was used for estimation of antioxidant activities. The alcoholic solution of DPPH radical $(0.5 \mathrm{~mL}, 0.2 \mathrm{mM})$ was added to $100 \mu \mathrm{L}$ of the sample extract, mixed vigorously and kept standing in dark for $40 \mathrm{~min}$. Then absorbance was measured at $517 \mathrm{~nm}$ and the capacity to scavenge DPPH radical was calculated using the formula: Scavenging $\left.(\%)=\left[\left(\mathrm{A}_{0}-\mathrm{A}_{1}\right) / \mathrm{A}_{0}\right)\right] \times 100$; where $\mathrm{A}_{0}$ is absorbance of the control reaction and $A_{1}$ is absorbance of the sample at $517 \mathrm{~nm}$. Inhibitory concentration at 50\% (extract concentration that cause $50 \%$ scavenging of $\mathrm{DPPH}$ radical, $\mathrm{IC}_{50}$ ) was also determined.

\section{Level of Protein Oxidation}

To measure the level of protein oxidation (PO), the sulfhydryl ( $\mathrm{SH})$ group of proteins was determined using Ellman's reagent [5,5'-dithiobis(2-nitrobenzoic acid)] following the procedure described by Ellman (1959). Shoot tissues (75 mg) were ground into fine powder and suspended in $10 \mathrm{~mL}$ phosphate buffer (0.1 M, pH 8.0) containing EDTA ( $1 \mathrm{mM})$ and SDS (1\%). The suspension was kept for stirring at $20^{\circ} \mathrm{C}$ for $30 \mathrm{~min}$. For $\mathrm{SH}$ determinations, $3 \mathrm{~mL}$ protein extract was added with $3 \mathrm{~mL}$ of 0.1 $M$ phosphate buffer containing EDTA, SDS, and $0.1 \mathrm{~mL}$ Ellman's reagent. The content was, mixed thoroughly by vortexing and incubated at $25^{\circ} \mathrm{C}$ for $1 \mathrm{~h}$. The mixture thus obtained was centrifuged at $10,000 \mathrm{rpm}$ for $30 \mathrm{~min}$ and absorbance of the supernatant was measured at $412 \mathrm{~nm}$ against the reagent blank. Calculation for $\mathrm{SH}$ group was based on extinction coefficient of $13,600 \mathrm{M}^{-1} \mathrm{~cm}^{-1}$ for thiolate-chromogen using the equation: $\mu \mathrm{MSH} \mathrm{g}^{-1}=73.53 \times \mathrm{A}_{412} \mathrm{~nm} \times \mathrm{D} / \mathrm{C}$, where $\mathrm{A}_{412}=$ absorbance at $412 \mathrm{~nm}, \mathrm{C}=$ sample concentration in $\mathrm{mg}$ solids $\mathrm{mL}^{-1}$, $\mathrm{D}=$ dilution factor (2.03) for $\mathrm{SH}$, and 73.53 is derived from $10^{6} /(13,600) ; 10^{6}$ is for conversion from the molar basis to $\mu \mathrm{M}$ $\mathrm{mL}^{-1}$ basis and from $\mathrm{mg}$ solid to g solid.

\section{Semi-quantitative Gene Expression Analysis}

To assess the effects of seed-priming and drought stress on expression of Rice Drought-responsive genes (RD1: EF362638 and RD2: KC988330), total RNA was isolated from shoot tissues of the contrasting rice genotypes under different treatments. RNA isolation, complimentary DNA (cDNA) synthesis and reverse transcription PCR (RT-PCR) were carried out with the gene-specific primers [RD1: FP $5^{\prime}$ TCGGCTGCGAAGGTGGCAGC-3', RP 5' - CACCGTGCAGCA
GCCCATGT-3'); RD2: FP 5'-CGCCTCAAAGAAGCGCTAC$3^{\prime}, \quad$ RP $5^{\prime}$-AGTGTCAAAGGTGCCAAGC-3'] following the procedure described elsewhere (Singh et al., 2015). Actin (UniGene cluster Os03G50885) was used as housekeeping/reference gene (FP 5'-GATCTGGCATCACA CCTTCTAC-3', RP 5'-CTGGGTCATCTTCTCACGATTG-3'). Amplification products were analyzed on agarose $(1.4 \%)$ gel electrophoresis.

\section{Quantitative Gene Expression Analysis}

To study differential expression of the RD1 and RD2 genes under different treatments, quantitative expression analysis of the genes was carried out following the MIQE guidelines and the protocol mentioned earlier (Singh et al., 2015). Three biological and three technical replications were used for the analysis. RTqPCR was performed in $20 \mu \mathrm{L}$ reaction mix on Mx3000PTM Real Time PCR system (CFX-96, Bio-Rad Platform) with SYBR Green qPCR Master Mix kit (Bio-Rad; Cat. \# 170-8880AP) using gene-specific primers. The thermal cycler was programmed for an initial denaturation at $95^{\circ} \mathrm{C}$ for $3 \mathrm{~min}$, followed by 39 cycles each of $20 \mathrm{~s}$ denaturation at $94^{\circ} \mathrm{C}, 20 \mathrm{~s}$ annealing at $60^{\circ} \mathrm{C}$ and $40 \mathrm{~s}$ extension at $72^{\circ} \mathrm{C}$. Amplification data collection was set at the end of each extension step. The data was analyzed through melt curve analysis to check the specificity of PCR amplification. Pfaffl formula (Ratio $=2^{-\Delta \Delta \mathrm{Ct}}$ ) [where $\Delta \Delta \mathrm{Ct}=(\Delta \mathrm{Ct}$ sample- $\Delta \mathrm{Ct}$ control $) ; \Delta \mathrm{Ct}$ sample $=(\Delta \mathrm{Ct}$ target$\Delta \mathrm{Ct}$ reference) for all primed and unprimed samples; and $\Delta \mathrm{Ct}$ control $=(\Delta \mathrm{Ct}$ target- $\Delta \mathrm{Ct}$ reference $)](\mathrm{Pfaffl}, 2001)$ was used to calculate the relative expression of the RD1 and RD2 genes with actin (UniGene cluster Os03G50885) as reference/housekeeping gene.

\section{Statistical Analysis}

All the experiments were carried out in triplicate. The data were analyzed with the help of pre-loaded software in Excel, programmed for statistical calculations. Duncan's multiple range tests (DMRT) were performed to determine significant difference between means at a significance level of $P \leq 0.05$ and reported as the mean \pm standard deviation (SD).

\section{RESULTS}

\section{Seed-Priming Mitigates Damaging Effects of Drought Stress on the Plant}

Seed-priming with elicitor (MJ, SA or PB) showed beneficial effects on morphological features of the seedlings of droughttolerant $(\mathrm{N}-22)$ and drought-sensitive (PS-5) rice genotypes under drought stress. The plants raised from primed-seeds showed healthier growth under the stress compared to those raised from unprimed seeds. Physiological health of the plants raised from unprimed seeds of drought-tolerant $(\mathrm{N}-22)$ and drought-sensitive (PS-5) genotypes under control as well as drought stress condition was found to be poorer compared to that of the plants raised from the seeds primed with any of the elicitor (Figure 1). Comparative morphological observations 
on the plants revealed that response of the elicitors was better in case of the drought-sensitive genotype than that observed in the drought-tolerant genotype. $\mathrm{MJ}$ and $\mathrm{PB}$ were found to be more responsive than SA on seed-priming, providing better protection against the drought-stress in both the rice genotypes.

\section{Seed-Priming Increased Relative Water Content of Shoot under Drought Stress}

Measurement of the SMC in the pots on $0,2,4$, and 6 day of withholding irrigation indicated that a progressive decline in SMC occurred with the progress in the duration of drought stress (Supplementary Table S2). Initially, SMC of the pots was in the range of $50-65 \%$ while it was reduced to $26-36 \%$ on 4 th day, and $18-24 \%$ on 6 th day of the water-deficit stress. We observed that the stress of more than 4 days led to the threshold level; therefore, shoot tissues were collected after 4 days of the stress for the biochemical and molecular studies. RWC in shoot was found in the range of $80-96 \%$ in the plants of both the genotypes raised from primed and unprimed seeds under control (unstressed) condition (Figure 2). Drought stress caused decrease in the RWC of shoot of the plants from both primed and unprimed seeds. The decrease in RWC was significantly higher (56-58\%) in case of the plants from unprimed seeds than that (22-52\%) in the plants from primed seeds of the contrasting rice genotypes. RWC of the plants from MJ-primed seeds under the stress was found to be maximum (70 and 58\%), followed by the plants from PB-primed (58 and 52\%) and the plants from SA-primed (56 and 45\%) seeds of drought-tolerant and drought-sensitive genotypes, respectively. Thus, among the three elicitors used for seed-priming, reduction in RWC due to drought stress was found to be lowest in the plants from MJ-primed seeds (N-22, 21\% and PS-5, 27\%).

\section{Seed-Priming Increased Antioxidant Activities in Shoot under the Stress}

Total phenolics content was found to increase (10\%) on drought stress imposition in the drought-tolerant (N-22) genotype, while it was found to decrease (27\%) in the drought-sensitive (PS-5) genotype (Figure 3). Increase in TPC due to drought stress was found to be $45 \%$ in the plants raised from MJ-primed seeds of $\mathrm{N}-22$, while the increase was $15 \%$ in the plants raised from MJprimed seeds of PS-5. Significant increase in TPC on drought stress imposition in both the genotypes was also observed on seed-priming with $\mathrm{PB}$, while the increase was non-significant in the plants raised from the seeds primed with SA.

Antioxidant potential in terms of DDPH scavenging was found to increase $(7.5 \%)$ on drought stress imposition in
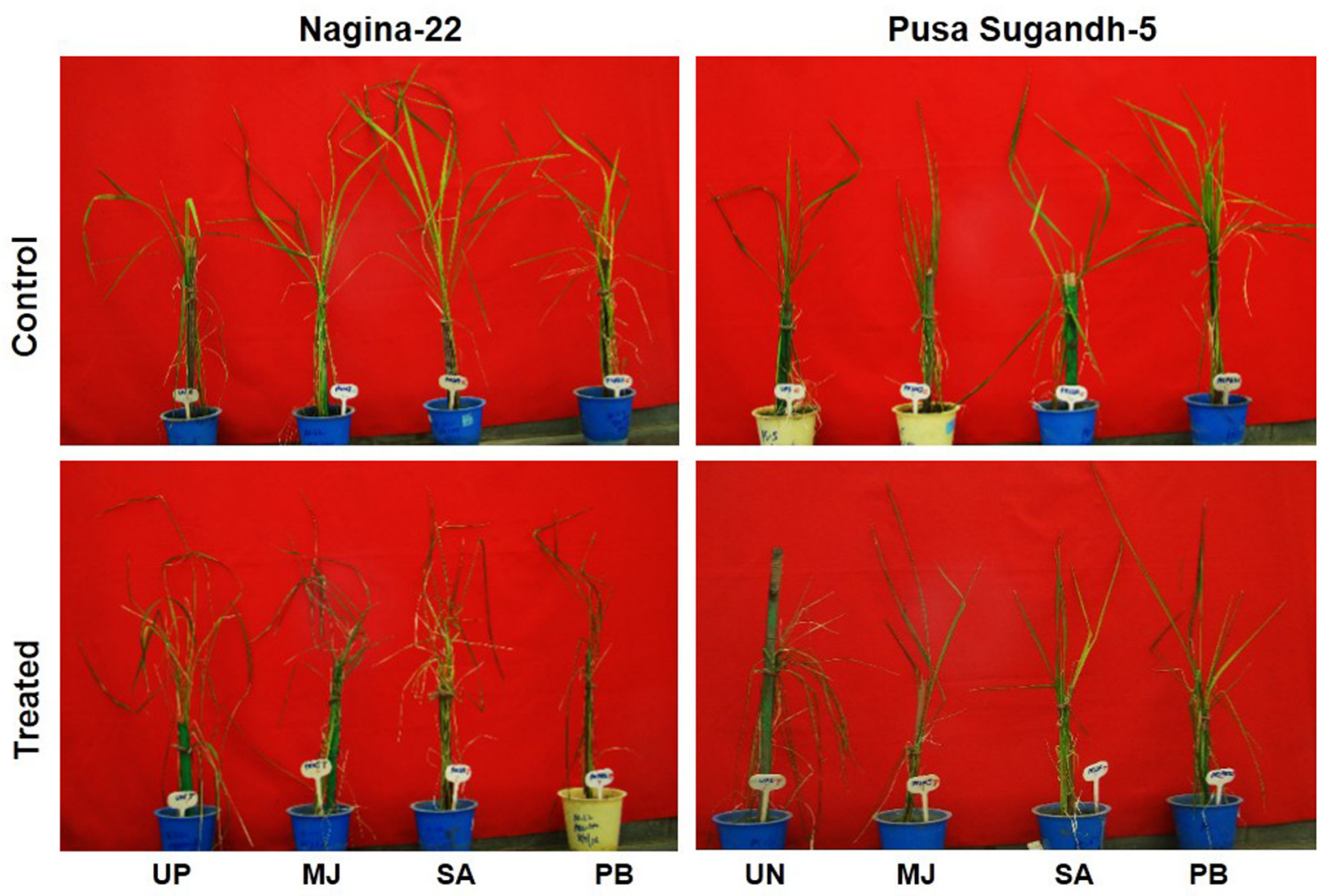

FIGURE 1 | Effect of seed-priming on mitigation of the deleterious effects of drought stress (withholding irrigation for 4 days) in 7 week old seedlings of Nagina-22 (N-22, drought-tolerant) and Pusa Sugandh-5 (PS-5, drought-sensitive) rice genotypes primed with $100 \mu \mathrm{M}$ of methyl jasmonate (MJ), salicylic acid (SA), or paclobutrazol (PB). UP, unprimed + no drought stress; MJ, MJ-priming; PB, PB-priming; SA, SA-priming. 


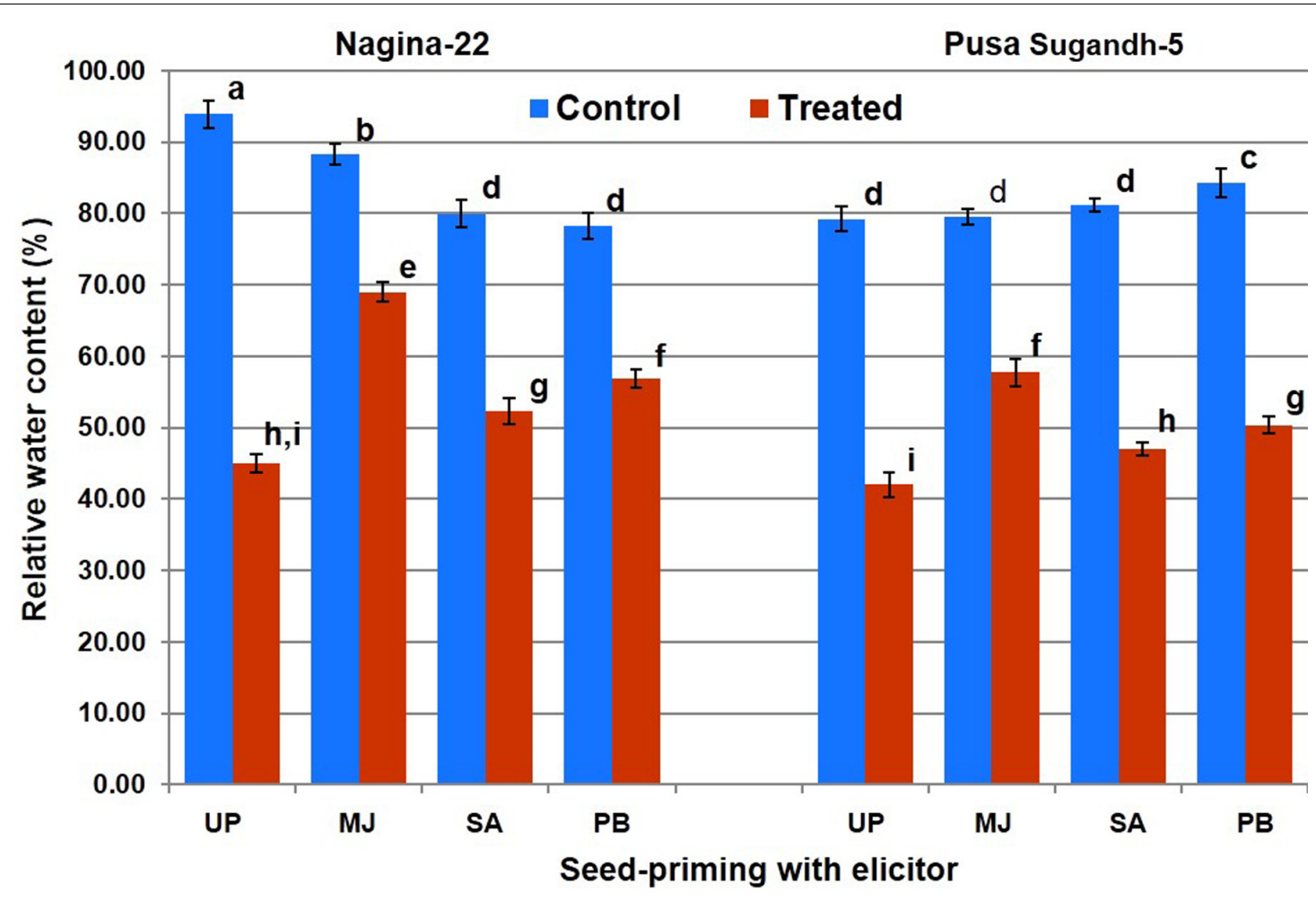

FIGURE 2 | Effect of seed-priming on relative water content in shoot of the contrasting rice genotypes [Nanina-22 (N-22, drought-tolerant) and Pusa Sugandh-5 (PS-5, drought-sensitive)] under control and drought stress conditions. UP, unprimed + no drought stress; MJ, MJ-priming; PB, PB-priming; SA, SA-priming. Columns with different lowercase letters indicate significant difference at $P<0.05$ (Duncan's multiple range test). Bar represents the standard deviation.

the drought-tolerant (N-22) genotype, while it was found to decrease $(20 \%)$ in the drought-sensitive (PS-5) genotype (Figure 4). Increase in antioxidant potential due to drought stress was found to be $22 \%$ in the N-22 plants raised from MJ-primed seeds, while the increase was $21 \%$ increase in the PS-5plants raised from MJ-primed seeds. Seed-priming with $\mathrm{PB}$ also showed significant increase in antioxidant potential on drought stress imposition in N-22 (51\%) and PS-5 (12\%), but seed-priming with SA caused decrease (54\%) in antioxidant potential in drought-sensitive genotype under the stress.

\section{Seed-Priming Lowered Lipid \\ Peroxidation in Shoot under the Stress}

Lipid peroxidation in terms of MDA level was found to decrease (21\%) in the drought-tolerant (N-22) genotype on drought stress imposition, while it was found to increase (45\%) in the droughtsensitive (PS-5) genotype (Figure 5). Seed-priming with the elicitors lowered LP on drought stress imposition in the shoot of both the genotypes. However, SA-priming was less efficient in mitigating LP in drought-sensitive (PS-5) genotype under the stress. Decrease in LP in N-22 under drought stress due to seed-priming with $\mathrm{MJ}$ was up to $58 \%$, while the decrease was $27 \%$ due to seed-priming with $\mathrm{PB}$. In case of droughtsensitive (PS-5) genotype, the decreased LP under drought stress due to seed-priming with MJ and PB was non-significant, while seed-priming with SA caused increase (23\%) in LP under drought stress.

\section{Seed-Priming Reduced Protein Oxidation in Shoot under the Stress}

Protein oxidation (PO) was found to be significantly higher in drought-sensitive (PS-5) genotypes compared to that in the drought-tolerant (N-22) genotype. Seed-priming with the elicitor reduced level of $\mathrm{PO}$ under the stress in both the genotypes (Figure 6). Priming with $\mathrm{PB}$ showed maximum decrease in the level of $\mathrm{PO}$, followed by $\mathrm{MJ}$ and $\mathrm{SA}$ in both the genotypes after drought stress imposition. $\mathrm{PB}$ primed drought treated sample showed maximum $(73 \%)$ decrease in PO level in the tolerant genotype, and up to $46 \%$ decrease in the sensitive genotype compared to the PO level in plants raised from unprimed seeds and grown under the stress. MJ treatment caused reduction in PO by 51 and $20 \%$ in the tolerant genotype and $46 \%$ decrease in sensitive genotype, respectively. SA showed 50\% decrease in $\mathrm{PO}$ in case of tolerant-genotype under the stress, while it was less effective in reducing $\mathrm{PO}$ in the drought-sensitive genotype.

\section{Seed-Priming Upregulated Expression of the $R D$ Genes under the Stress}

Semi-quantitative (RT-PCR) expression analysis of RD1 (EF362638 ) and RD2 (KC-988330) genes from AP2/ERF TF family, 


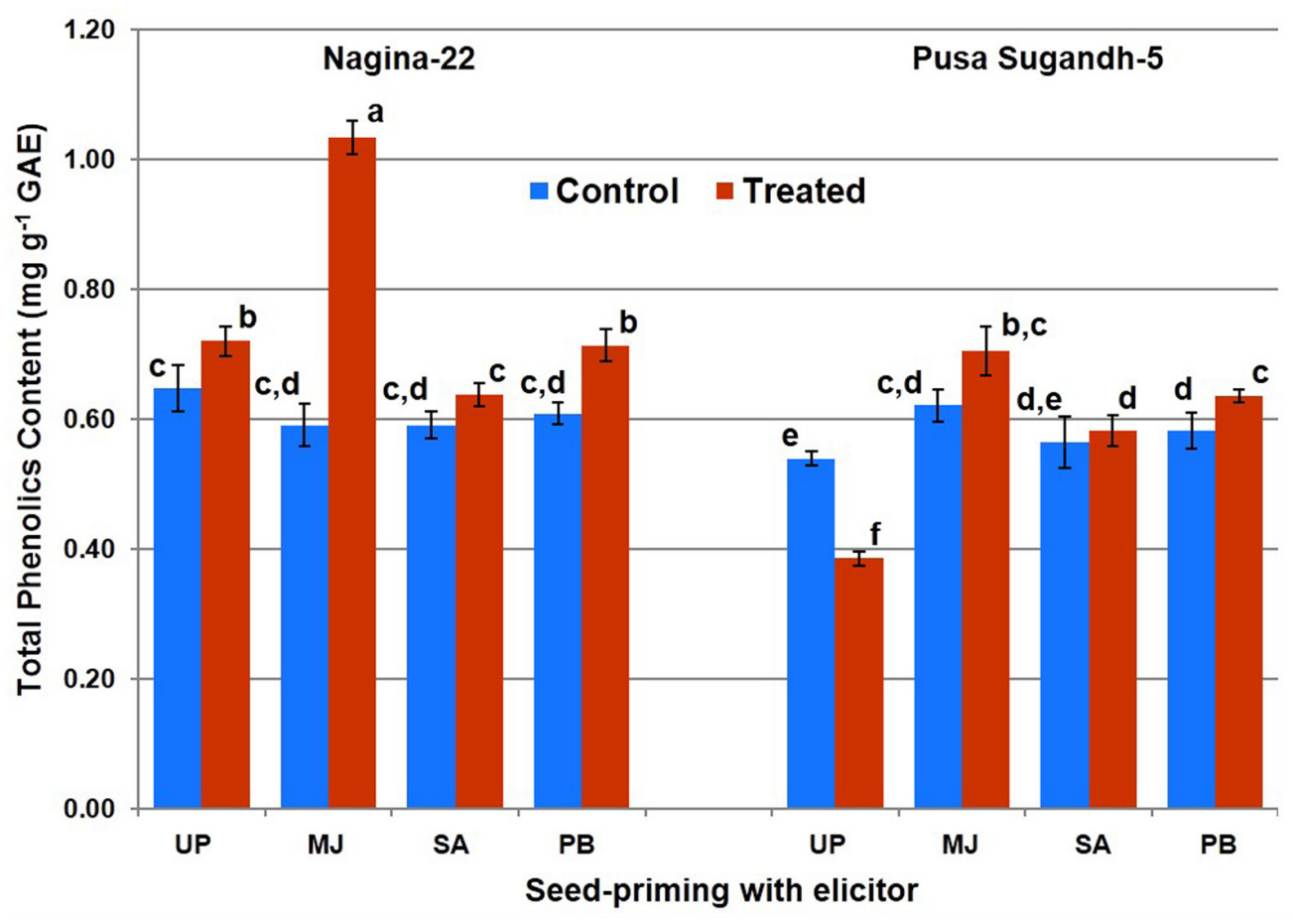

FIGURE 3 | Effect of seed-priming on total phenolic content in shoot of the contrasting rice genotypes [Nanina-22 (N-22, drought-tolerant) and Pusa Sugandh-5 (PS-5, drought-sensitive)] under control and drought stress conditions. Columns with different lowercase letters indicate significant difference at $P<0.05$ (Duncan's multiple range test). Bar represents the standard deviation.

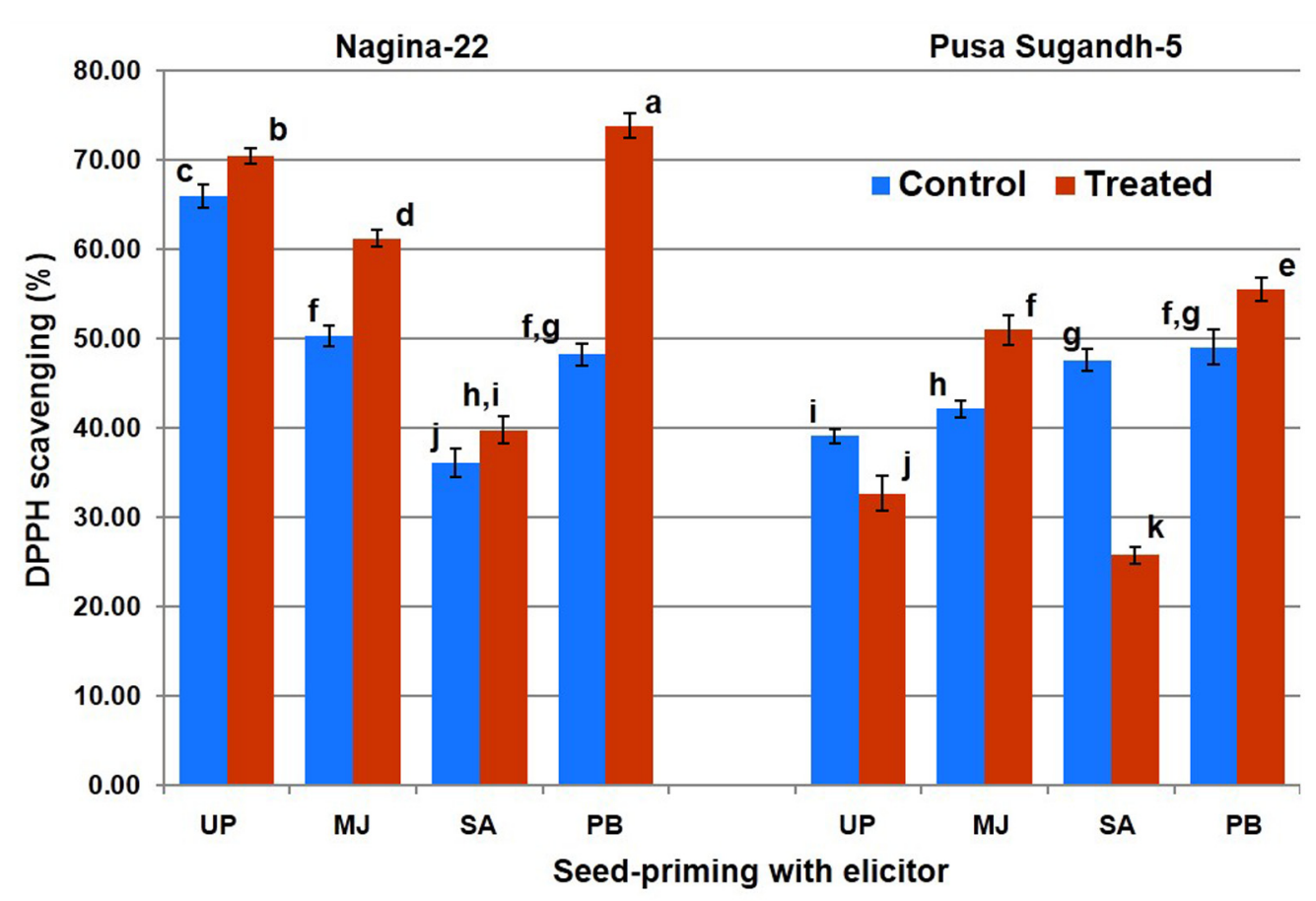

FIGURE 4 | Effect of seed-priming on antioxidant activity (DPPH scavenging \%) in shoot of the contrasting rice genotypes [Nanina-22 (N-22, drought-tolerant) and Pusa Sugandh-5 (PS-5, drought-sensitive)] under control and drought stress conditions. UP, unprimed + no drought stress; MJ, MJ-priming; PB, PB-priming; SA, SA-priming. Columns with different lowercase letters indicate significant difference at $P<0.05$ (Duncan's multiple range test). Bar represents the standard deviation. 


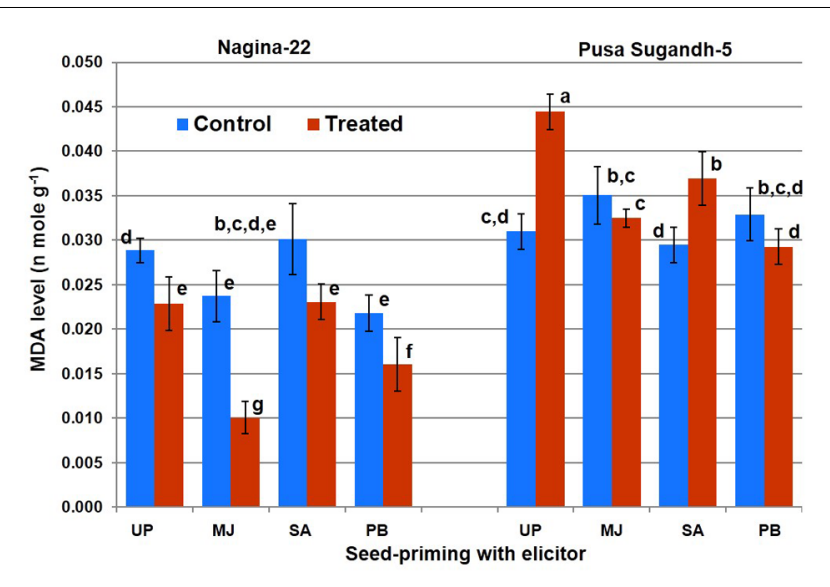

FIGURE 5 | Effect of seed-priming on lipid peroxidation (MDA level) in shoot of the contrasting rice genotypes [Nanina-22 (N-22, drought-tolerant) and Pusa Sugandh-5 (PS-5, drought-sensitive)] under control and drought stress conditions. UP, unprimed + no drought stress; MJ, MJ-priming; PB, PB-priming; SA, SA-priming. Columns with different lowercase letters indicate significant difference at $P<0.05$ (Duncan's multiple range test). Bar represents the standard deviation.

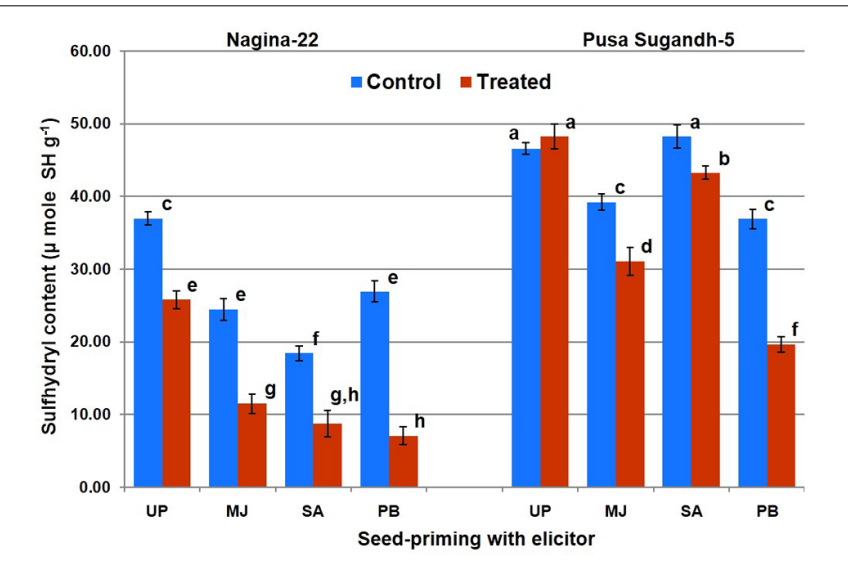

FIGURE 6 | Effect of seed-priming on protein oxidation (sulfhydril content) in shoot of the contrasting rice genotypes [Nanina-22 (N-22, drought-tolerant) and Pusa Sugandh-5 (PS-5, drought-sensitive)] under control and drought stress conditions. UP, unprimed + no drought stress; MJ, MJ-priming; PB, PB-priming; SA, SA-priming. Columns with different lowercase letters indicate significant difference at $P<0.05$ (Duncan's multiple range test). Bar represents the standard deviation.

in shoot of the plants raised from the seeds of the contrasting rice genotype (N-22, drought-tolerant and PS-5, drought-sensitive) primed with an elicitor (MJ, SA, or PB) showed that the genes were differentially expressed under control and drought stress conditions (Figure 7). Seed-priming was found to upregulate expression level of the genes in shoot of both the genotype under drought stress. In the drought-tolerant genotype under the stress, the increase in expression level of $R D 1$ gene due to seed-priming with MJ was more prominent than that with PB and SA. Whereas, the increase in expression level of RD2 gene in the droughttolerant genotype under the stress was more prominent due to

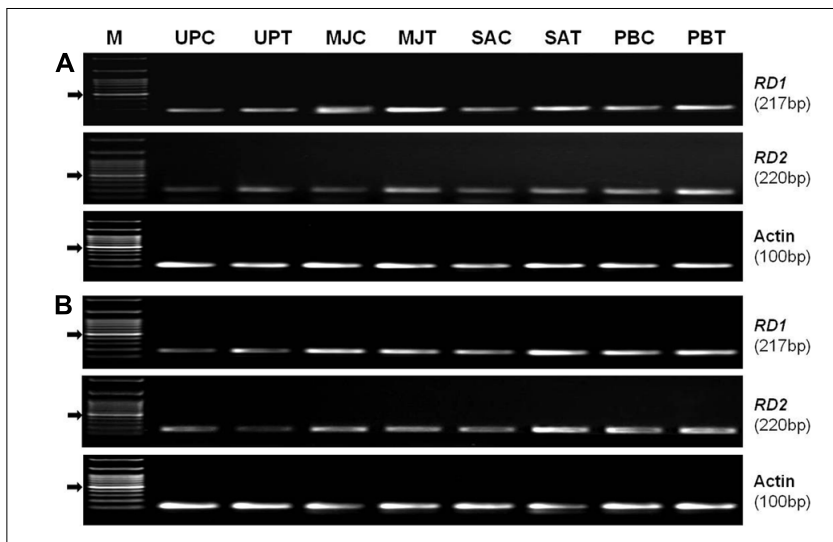

FIGURE 7 | Semi-quantitative (RT-PCR) expression profile of $R D 1$ and $R D 2$ genes in shoot of the plants raised from the seeds of contrasting rice genotype (A) Nanina-22 (N-22, drought-tolerant) and (B) Pusa Sugandh-5 (PS-5, drought-sensitive) without priming or priming with different elicitor grown under control and drought stress (witholding irrigation for 4 days) conditions. Actin was used as reference gene. UPC: unprimed, unstressed (control); UPT: unprimed, stressed (treated with stress); MJC: MJ-primed, control; MJT: MJ-primed, treated; SAC: SA-primed, control; SAT: SA-primed, treated; PBC: PB-primed, control; PBT: PB-primed, treated.

seed-priming with PB (Figure 7A). In case of drought-sensitive genotype under the stress, the increase in expression level of both the genes were found to be more due to seed-priming with $\mathrm{SA}$ and $\mathrm{PB}$ than that due to seed-priming with MJ (Figure 7B). Expression level of the housekeeping/reference (Actin) gene was observed to be constant in primed and unprimed, control and stressed samples of both the rice genotypes.

Quantitative (RT-qPCR) expression analysis of $R D 1$ and $R D 2$ genes in shoot of the rice plants raised from the seeds of the contrasting rice genotype primed with the elicitor clearly showed differential expression of the genes under control and drought stress conditions (Figure 8). Expression level of the genes was found to be upregulated due to the stress in drought-tolerant genotype, while it was found to be downregulated in the drought-sensitive genotype. Seed-priming with MJ significantly increased expression of the genes even under control condition, and drought stress further increased the expression of these genes. MJ induced expression level of the RD1 gene in N-22 under drought stress by 2.6fold, while 1.6-fold in case of PS-5. Seed-priming with PB also increased expression level of the gene significantly (2fold) in N-22 under drought stress, but the increase in expression level of the gene due to SA-priming was found to be less compared to that caused by MJ and PB priming. Expression of RD2 was found to be increased significantly under drought stress due to seed-priming with the elicitors. It was found to be maximum (3.7-fold) on priming with $\mathrm{PB}$ in case of $\mathrm{N}-22$, and 2.2-fold in case of PS-5 on SA-priming. Comparative analysis indicated that the effect of seed-priming was more influential on expression of the gene in the drought-sensitive genotype (converting its downregulated expression to upregulated expression under the stress) than that in the drought-tolerant genotype. 

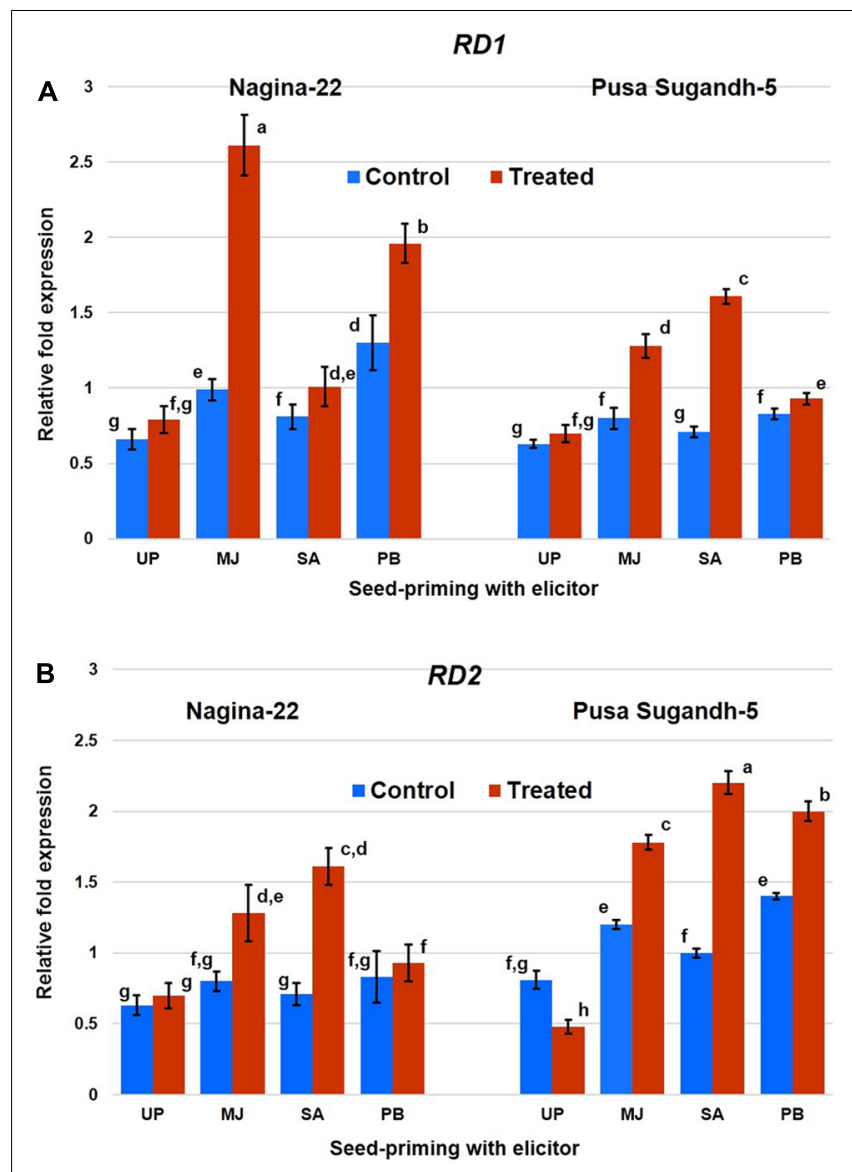

FIGURE 8 | Quantitative (RT-qPCR) expression profile of (A) $R D 1$ and (B) $R D 2$ genes in shoot of the plants raised from the seeds of contrasting rice genotypes (Nanina-22, drought-tolerant and Pusa Sugandh-5,

drought-sensitive) without priming or priming with different elicitor grown under control and drought stress (witholding irrigation for 4 days). The results are represented as mean fold change in relative expression over three biological and three technical replicates, normalized with respect to actin as housekeeping/reference gene. UP, unprimed; MJ, MJ-primed; SA, SA-primed; PB, PB-primed. Columns with different lowercase letters indicate significant difference at $P<0.05$ (Duncan's multiple range test). Bar represents the standard deviation.

\section{DISCUSSION}

Most of the rice varieties are severely affected by abiotic stresses (Almeida et al., 2016). Among the abiotic stresses, drought stress alone or in combination with other abiotic stress(es) causes severe damages to the crop plants, which result in reduced growth, development and productivity of the crop. Our morphological observations clearly indicated that the two contrasting rice genotypes (N-22, drought-tolerant and PS-5, drought-sensitive) displayed distinct variation in growth under drought stress during vegetative growth. The observed reduction in the growth might be due low osmotic potential as well as due to the decrease in cell wall extensibility (Grieve et al., 2001; Haplerin and Lynch, 2003). Despite of very low SMC (25-35\%), MJ was found to be more effective in maintaining high RWC (58-69\%) in shoot compared to that $(42-45 \%)$ in the plants raised from unprimed seeds under drought stress in both drought-tolerant and drought-sensitive genotypes. The effects of seed-priming could be correlated with the better health and growth of the plants under drought stress compared to that of the plants from unprimd seeds (Figure 1). Seed-priming with different elicitor could significantly (12-53\%) increase RWC in shoot under the stress compared to that in the plants from unprimd seeds. Recently, the effect of drought stress on shoot RWC was reported to be associated with the tuber yield in potato (Soltys-Kalina et al., 2016). RWC is considered as a useful indicator of plant health status under drought stress (Chaves et al., 2002; Mawlong et al., 2014), and shows relationship with yield parameters (Gutierrez et al., 2010).

Seed-priming with PB caused significant increase in TPC on drought stress imposition in both the genotypes, while MJ showed significant increase in case of the tolerant genotype (Figure 2). Seed-priming with $\mathrm{MJ}$ and $\mathrm{PB}$ was found to increase $\mathrm{AO}$ activity in drought-sensitive genotype which may improve drought tolerance ability of the genotype. On the contrary, we observed SA to decrease AO activity by $45 \%$ in the drought-sensitive genotype (Figure 4), which might be acting as antagonist (Jisha et al., 2015). A positive correlation between TPC and AO activity has been reported earlier to impart abiotic stress tolerance in plants (Trust et al., 2005; Rao et al., 2013). Thus, the contrasting genotypes responded differently (in terms of their antioxidant potential) to seed-priming with different elicitor. Though seed-priming with SA could not increase TPC content (positively correlated with drought stress tolerance) significantly in both the genotypes (Figure 3), it caused significant reduction in PO (negatively correlated with drought stress tolerance) under the stress (Figure 6). We observed reduced accumulation of MDA in drought-tolerant (N-22) genotype compared to that in the drought-sensitive (PS5 ) in the plants raised from unprimed seeds under the stress. MDA level increases under drought stress due to peroxidation of unsaturated fatty acids in phospholipids, and LP has been used as an indicator of free radical damage to cell membrane under stress conditions (Jaleel et al., 2007). Seed-priming with SA did not show beneficial effect on MDA level (negatively correlated with drought stress tolerance) in case of droughttolerant rice genotype, but significant increase in MDA level was observed in case of the drought-sensitive genotype (Figure 5). To overcome the deleterious effects of oxidative stress, plants make use of a complex antioxidant systems and accumulate phenolic compounds to minimize the damages caused by the free radicals resulting into lower LP and cell membrane damages. Farooq et al. (2008) and Khan et al. (2012) reported beneficial effects of seed-priming in terms of better germination, more vigorous growth, early flowering and higher yield. In the present study, we observed significant retardation in the growth and development of contrasting rice genotypes under drought-stress which is in agreement with the observations reported earlier (Afzal et al., 2006; Bhargava et al., 2015). It may be due to the reduced water potential, increased reactive oxidant potential and membrane damages. Salah et al. (2015) and Hussain et al. (2016a,b) also described the significance of seed-priming 
in mitigating drought, chilling and submergence stresses in rice.

Transcription factors play crucial role in response of the plants to abiotic stresses. Genome-wide analysis of AP2/ERF genes and their expression in rice has been reported to play important role in stress tolerance (Tang et al., 2016). We observed differential expression of $R D 1$ and $R D 2$ genes in shoot of the contrasting rice genotype (Figure 8). The genes were found to be upregulated under the stress in drought-tolerant genotype while it was downregulated in the drought-sensitive genotype. Seed-priming with elicitor significantly increased expression level of both the genes, particularly under drought stress in the drought-sensitive genotype. However, expression of $R D 2$ gene was more significantly induced [from downregulated expression in the drought-sensitive genotype (PS-5) under the stress] to more than 2-fold upregulated expression due to seed-priming under the stress. Recently, Wei et al. (2016) reported ectopic expression of a TF (DREB1A) in Arabidopsis showing higher RWC, chlorophyll content, photosynthetic rate, increased superoxide dismutase, catalase, peroxidase activities and lower MDA level when subjected to drought stress. All of these resulted into increased drought tolerance in the transgenic lines.

A model depicting various possible physio-biochemical and bio-molecular responses in plant cell under drought stress is presented in Figure 9. The stress is sensed through cell membrane, transduced to various inducers to regulate structural and molecular alterations including hydrogen peroxide accumulation, induction of AP2/ERF TF genes and transcriptional/translational reprogramming for protective

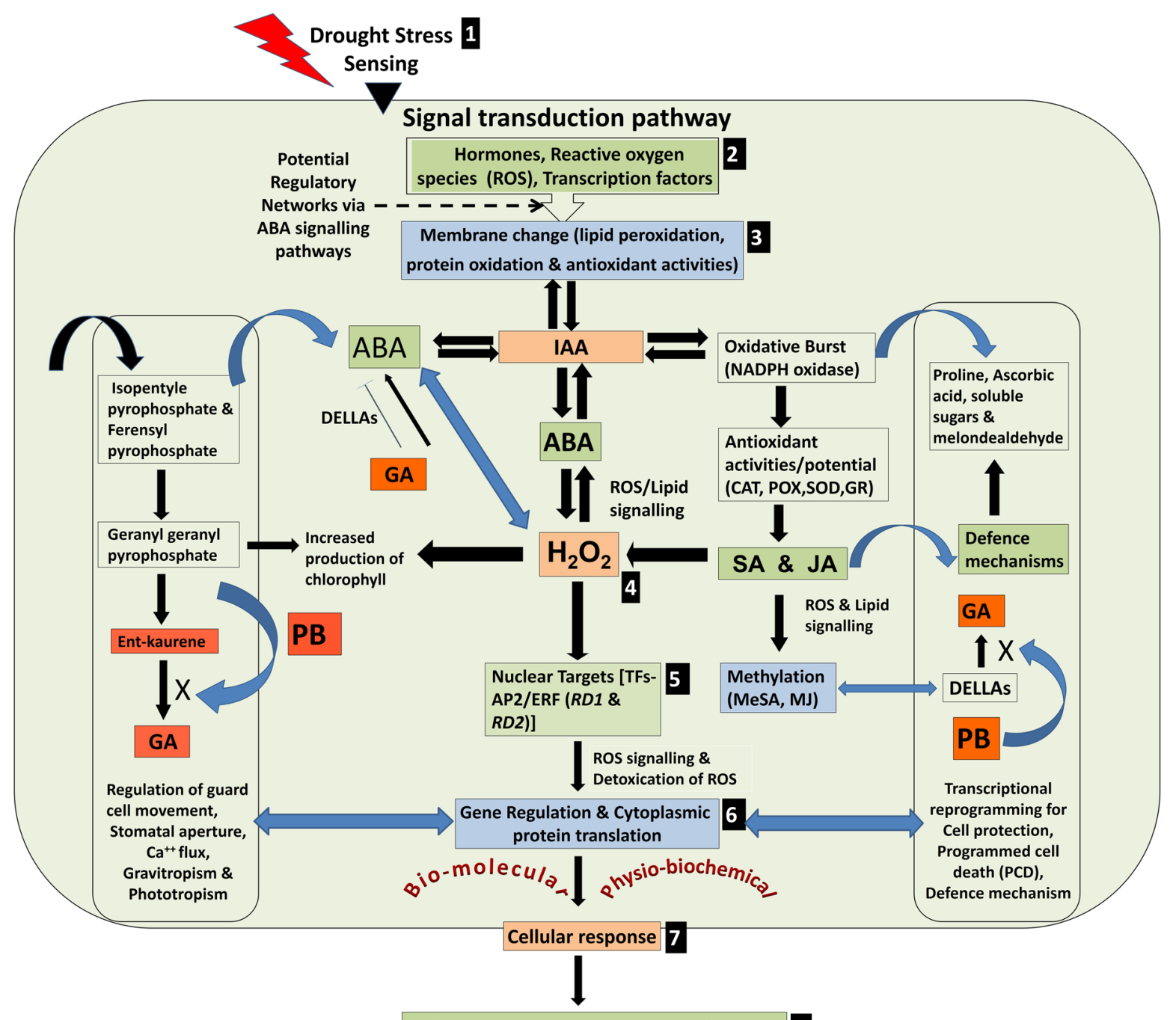

Enhanced drought stress tolerance 8

FIGURE 9 | Model depicting various possible physio-biochemical and bio-molecular responses under drought stress. (1) Stress sensing, (2) Signal transduction through various inducers, (3) Membrane alterations, (4) Hydrogen peroxide accumulation $\left(\mathrm{H}_{2} \mathrm{O}_{2}\right)$ through potential regulatory networks, (5) Induction of AP2/ERF transcription factor genes (RD1 and RD2), (6) Transcriptional and translational reprogramming to combat the stress, (7) cellular responses, and (8) enhanced drought tolerance. 
defense mechanism. We observed a better response of $\mathrm{MJ}$ followed by $\mathrm{PB}$ to induce the defense responses of rice against drought stress. The effects of seed-priming were beneficial for growth and development of the rice plants not only under the stress but also under control condition in the plants raised from primed seeds (Figure 1). This indicated that seed-priming with elicitor did not adversely affected metabolic pathways in the plants under normal (unstressed) condition. In turn, it lays foundation toward the development of an easier, efficient and economic technique toward improving drought stress tolerance in rice. Characterization of gene encoding jasmonic acid carboxy methyl transferase has provided information on the role(s) of phytohormone in gene activation and systemic long-distance signaling (Cheong and Choi, 2003). Salzman et al. (2005) and Jisha et al. (2015) reported transcriptional cross-talk between SA and MJ indicating their antagonism and synergism in gene regulation and signaling cascade.

Transgenic rice plants overexpressing AP2/ERF TF (OsEREBP1) showed increase in endogenous levels of $\alpha$-linolenate, several jasmonate derivatives and ABA but not SA. The level of ABA was $\sim 2$-fold higher in the transgenic plants as compared to non-transgenic control, whereas SA levels showed no significant difference (Jisha et al., 2015). By contrast, we observed that seed-priming with SA caused maximum increase in the expression of $R D 1$ and $R D 2$ in drought-sensitive genotype under drought stress. But in case of drought-tolerant genotype, $R D 1$ did not show significant increase while $R D 2$ showed $\sim 2$-fold increase under the stress. It suggests that function of SA is ambiguous because at physio-biochemical level it acts as an antagonist, while synergistic at gene expression level. Lipids are found to be connected to the plant defense responses through potential action as a signaling molecules (Laxalt and Munnik, 2002) through the fatty acid- linolenic acid, acting as the precursor for 12- oxo-phytodienoic acid (OPDA) and JA synthesis via octadecanoid pathway (Creelman and Mullet, 1997). Suppression of plant growth by PB occurs because it blocks three separate steps (Geranylgeranyl pyrophosphate $\rightarrow$ Ent-kaurene $\rightarrow$ GA) in the terpenoid pathway for the production of gibberellins which diverts isopentyle pyrophosphate and ferensyl pyrophosphate (secondary metabolites) toward ABA biosynthesis (Figure 9).

Findings here indicated that RWC, total phenolic content (TPC), LP, protein oxidation and antioxidant (AO) activity are crucial biochemical markers of drought tolerance. Both RD1 and $R D 2$ genes were upregulated under drought stress, and seedpriming with $\mathrm{MJ}, \mathrm{PB}$ and SA further increased expression of both of the genes of AP2/ERF TFs. There was a progressive increase in TPC, LP, AO and protein oxidation activity in primed samples during drought stress imposition and increase was found to be of higher magnitude in the drought-susceptible genotype than that of the tolerant one. This indicates that elicitor enhances drought tolerance and plays important role in eliciting defense mechanisms against abiotic stress. Seed-priming enhanced drought tolerance in drought-sensitive genotype at much higher level than that in drought-tolerant rice genotype. The elicitors were found to mitigate the effect of drought stress by affecting expression of $R D 1$ and $R D 2$ genes as well affecting biochemical and physiological parameters. The great leaps and bounds toward understanding plant's drought stress responses and tolerance mechanisms have been achieved in the past years; however, many challenges still lie ahead and plant breeders face serious difficulties in developing superior cultivars with broad spectrum of abiotic resistance. The regulation of gene expressions and signaling cascades that regulate defense mechanism remain to be elucidated. Thus, present findings will facilitate insight in unraveling elicitor induced biochemical and molecular manifestations of drought tolerance in rice to improve crop yield.

\section{CONCLUSION}

Our findings confirmed that RWC, TPC, LP, PO and AO activity are important biochemical markers of drought stress tolerance in plants. A progressive increase in TPC and AO activities, while decrease in LP and PO were observed under drought stress in the plants raised from the seeds primed with elicitor (MJ or $\mathrm{PB}$ ). The increase was found to be of higher magnitude in the drought-sensitive genotype (PS-5) than that of the droughttolerant one. The drought-responsive (RD1 and RD2) genes of AP2/ERF TF family were upregulated on drought stress, and seed-priming with the elicitors increased expression of the genes in the contrasting rice genotypes. This indicates that elicitor may play important role in mitigating abiotic stress in plants, particularly in the sensitive genotypes. Considerable progress has been made toward understanding the stress responses and tolerance mechanisms in plants in the past (Zhu, 2016). This indicates that seed-priming with elicitor does not adversely affect metabolic pathways in the plants under normal (unstressed) condition. In turn, it lays foundation toward the development of an easier, efficient and economic technique toward improving drought stress tolerance in rice. However, there is need to validate the efficacy of the seed-priming technique for improving yield of rice under drought stress in the field conditions. Our results also suggest that genetic manipulation of RD1 and RD2 genes of the AP2/ERF family may enhance production of secondary metabolites resulting in improved drought stress tolerance (Mawlong et al., 2015). Epigenetic regulation of gene expression (Wang et al., 2016) under abiotic stresses (Kumar and Singh, 2016; Kumar et al., 2017) and signaling cascades (Bernsdorff et al., 2016; Ji et al., 2016) that regulate defense mechanisms remain to be elucidated. The present findings would facilitate unraveling the elicitor induced biochemical and molecular manifestations of drought tolerance in crop plants to improve the yield.

\section{AUTHOR CONTRIBUTIONS}

AS and SK conceptualized, initiated and designed the research work, and wrote the manuscript; MKS, MS, and MA carried out the biochemical and molecular studies, data collection and their analysis; AT and SAM helped in critical assessment and execution of experimental plan, OY helped in maintaining experimental materials, conducting the experiments under controlled conditions, sample collection, etc. 


\section{FUNDING}

The research work was supported by the Institutional funds provided by the ICAR-Indian Agricultural Research Institute, New Delhi, India.

\section{REFERENCES}

Afzal, I., Basra, S. M. A., Farooq, M., and Nawaz, A. (2006). Alleviation of salinity stress in spring wheat by hormonal priming with ABA, salicylic acid and ascorbic acid. Int. J. Agric. Biol. 8, 23-28.

Almeida, D. M., Almadanim, C. M., Lourenço, T., Abreu, I. A., Nelson, J. M., Saibo, N. J. M., et al. (2016). Screening for abiotic stress tolerance in rice: salt, cold, and drought. Methods Mol. Biol. 1398, 3-14. doi: 10.1007/978-1-4939-3356-3_14

Ashraf, M., and Rauf, H. (2001). Inducing salt tolerance in maize (Zea mays L.) through seed priming with chloride salts: growth and ion transport at early growth stages. Acta Physiol. Plant. 23, 407-417. doi: 10.1007/s11738-0010050-9

Bandurska, H., Stroiński, A., and Kubiś, J. (2003). The effect of jasmonic acid on the accumulation of ABA, proline and spermidine and its influence on membrane injury under water deficit in two barley genotypes. Acta Physiol. Plant. 25, 279-285. doi: 10.1007/s11738-003-0009-0

Barr, H. D., and Weatherley, P. E. (1962). A re-examination of the relative turgidity technique for estimating water deficit in leaves. Aust. J. Biol. Sci. 15, 413-428. doi: 10.1071/BI9620413

Bayat, S., and Sepehri, A. (2012). Paclobutrazol and salicylic acid application ameliorates the negative effect of water stress on growth and yield of maize plants. Int. J. Res. Agric. Sci. 8, 127-139.

Belda-Palazon, B., Nohales, M. A., Rambla, J. L., Acena, J. L., Delgado, O., Fustero, S., et al. (2014). Biochemical quantitation of the eIF5A hypusination in Arabidopsis thaliana uncovers ABA-dependent regulation. Front. Plant Sci. 16:e0202. doi: 10.3389/fpls.2014.00202

Bernsdorff, F., Döring, A.-C., Gruner, K., Schuck, S., Bräutigam, A., and Zeier, J. (2016). Pipecolic acid orchestrates plant systemic acquired resistance and defense priming via salicylic acid-dependent and -independent pathways. Plant Cell 28, 102-129. doi: 10.1105/tpc.15.00496

Bhargava, B., Gupta, Y. C., Dhiman, S. R., and Sharma, P. (2015). Effect of seed priming on germination, growth and flowering of Snapdragon (Antirrhinum majus L.). Natl. Acad. Sci. Lett. 38, 81-85. doi: 10.1007/s40009-014-0298-4

Cakmak, I., and Horst, J. H. (1991). Effects of aluminum on lipid peroxidation, superoxide dismutase, catalase, and peroxidase activities in root tips of soybean (Glycine max). Physiol. Plant. 83, 463-468. doi: 10.1111/j.1399-3054.1991. tb00121.x

Chaves, M. M., Pereira, J. S., Maroco, J., Rodrigues, M. L., Ricardo, C. P. P., Osorio, M. L., et al. (2002). How plants cope with drought in the field? Photosynthesis and growth. Ann. Bot. 89, 907-916. doi: 10.1093/aob/mcf105

Chen, K., Arora, R., and Arora, U. (2010). Osmopriming of spinach (Spinacia oleracea L. cv. Bloomsdale) seeds and germination performance under temperature and water stress. Seed Sci. Technol. 38, 36-48. doi: 10.15258/sst. 2010.38.1.04

Cheong, J. J., and Choi, Y. D. (2003). Methyl jasmonate as a vital substance in plants. Trends Genet. 19, 409-413. doi: 10.1016/S0168-9525(03)00138-0

Creelman, R. A., and Mullet, J. E. (1997). Biosynthesis and action of jasmonates in plants. Annu. Rev. Plant Physiol. Plant Mol. Biol. 48, 355-381. doi: 10.1146/ annurev.arplant.48.1.355

Dey, A., Samanta, M. K., Gayen, S., Sen, S. K., and Maiti, M. K. (2016). Enhanced gene expression rather than natural polymorphism in coding sequence of the OsbZIP23 determines drought tolerance and yield improvement in rice genotypes. PLoS ONE 11:e0150763. doi: 10.1371/journal.pone.0150763

Ellman, G. L. (1959). Tissue sulfhydryl groups. Arch. Biochem. Biophys. 82, 70-77. doi: 10.1016/0003-9861(59)90090-6

Farooq, M., Basra, S. M. A., Hafeezu, R., and Salem, B. A. (2008). Seed priming enhance the performance of late sown wheat by improving chilling tolerance. J. Agron. Crop Sci. 194, 55-60. doi: 10.1111/j.1439-037X.2007.00287.x

Fujita, M., Fujita, Y., Noutoshi, Y., Takahashi, F., Narusaka, Y., YamaguchiShinozaki, K., et al. (2006). Crosstalk between abiotic and biotic stress

\section{SUPPLEMENTARY MATERIAL}

The Supplementary Material for this article can be found online at: http://journal.frontiersin.org/article/10.3389/fpls.2017.00934/ full\#supplementary-material

responses: a current view from the points of convergence in the stress signaling networks. Curr. Opin. Plant Biol. 9, 436-442. doi: 10.1016/j.pbi.2006.05.014

Grieve, C. M., Poss, J. A., Suarez, D. L., and Dierig, D. A. (2001). Lesquerella growth and selenium uptake affected by saline irrigation water composition. Ind. Crops Prod. 13, 57-65. doi: 10.1016/S0926-6690(00)00053-4

Gutierrez, M., Reynolds, M. P., and Klatt, A. R. (2010). Association of water spectral indices with plant and soil water relations in contrasting wheat genotypes. J. Exp. Bot. 61, 3291-3303. doi: 10.1093/jxb/erq156

Haplerin, S. J., and Lynch, J. P. (2003). Effects of salinity on cytosolic $\mathrm{Na}^{+}$and $\mathrm{K}^{+}$ in root hairs of Arabidopsis thaliana: in vivo measurements using the fluorescent dyes SPFI and PBFI. J. Exp. Bot. 54, 2035-2043. doi: 10.1093/jxb/erg219

Hasanuzzaman, M., and Fujita, M. (2011). Selenium pre-treatment upregulates the antioxidant defense and methylglyoxal detoxification system and confers enhanced tolerance to drought stress in rapeseed seedlings. Biol. Trace Elem. Res. 143, 1758-1776. doi: 10.1007/s12011-011-8998-9

Hatano, T., Kagawa, H., Yasuhara, T., and Okuda, T. (1988). Two new flavonoids and other constituents in licorice root, their relative astringency and radical scavenging effects. Chem. Pharm. Bull. 36, 2090-2097. doi: 10.1248/cpb.36.2090

Hussain, S., Hanqi, Y., Deng, S., and Khan, F. (2016a). Comparative transcriptional profiling of primed and non-primed rice seedlings under submergence stress. Front. Plant Sci. 7:1125. doi: 10.3389/fpls.2016.01125

Hussain, S., Khan, F., Hussain, H. A., and Nie, L. (2016b). Physiological and biochemical mechanisms of seed priming-Induced chilling tolerance in rice cultivars. Front. Plant Sci. 7:116. doi: 10.3389/fpls.2016.00116

Jaleel, C. A., Gopi, R., Sankar, B., Manivannan, P., Kishore Kumar, A., Sridharan, R., et al. (2007). Studies on germination, seedling vigour, lipid peroxidation and proline metabolism in Catharanthus roseus seedlings under salt stress. S. Afr. J. Bot. 73, 190-195. doi: 10.1016/j.sajb.2006.11.001

Ji, Y., Liu, J., and Xing, D. (2016). Low concentrations of salicylic acid delay methyl jasmonate-induced leaf senescence by up-regulating nitric oxide synthase activity. J. Exp. Bot. 67, 5233-5245. doi: 10.1093/jxb/erw280

Jisha, K. C., Vijayakumari, K., and Puthur, J. T. (2013). Seed priming for abiotic stress tolerance: an overview. Acta Physiol. Plant. 35, 1381-1396. doi: 10.1007/ s11738-012-1186-5

Jisha, V., Dampanaboina, L., Vadassery, J., Mithöfer, A., Kappara, S., and Ramanan, R. (2015). Overexpression of an AP2/ERF type transcription factor OsEREBP1 confers biotic and abiotic stress tolerance in rice. PLoS ONE 10:e0127831. doi: 10.1371/journal.pone.0127831

Khan, M. I. R., Iqbal, N., Masood, A., Per, T. S., and Khan, N. A. (2013). Salicylic acid alleviates adverse effects of heat stress on photosynthesis through changes in proline production and ethylene formation. Plant Signal. Behav. 8:e26374. doi: $10.4161 /$ psb. 26374

Khan, S. U., Bano, A., Din, J. U., and Gurmani, A. R. (2012). Abscisic acid and salicylic acid seed treatment as potent inducer of drought tolerance in wheat. Pak. J. Bot. 44, 43-49.

Khush, G. S. (2005). What it will take to feed 5.0 billion rice consumers in 2030 . Plant Mol. Biol. 59, 1-6. doi: 10.1007/s11103-005-2159-5

Kumar, S., Beena, A. S., Awana, M., and Singh, A. (2017). Salt-induced tissuespecific cytosine methylation downregulates expression of HKT genes in contrasting wheat (Triticum aestivum L.) genotypes. DNA Cell Biol. 36:e3505. doi: $10.1089 /$ dna.2016.3505

Kumar, S., and Singh, A. (2016). Epigenetic regulation of abiotic stress tolerance in plants. Adv. Plants Agric. Res. 5:e00179. doi: 10.15406/apar.2016.05.00179

Kumar, S., Singh, R., Kalia, S., Sharma, S. K., and Kalia, R. (2016). Recent advances in understanding the role of growth regulators in plant growth and development in vitro-I: conventional growth regulators. Indian For. 142, 459-470.

Kumari, S., Dahuja, A., Vinutha, T., Lal, S. K., Kar, A., and Rai, R. D. (2015). Change in the level of off-flavor generation in soybean through biotic elicitor treatment. J. Agric. Food Chem. 63, 700-706. doi: 10.1021/jf505199a 
Laxalt, A. M., and Munnik, T. (2002). Phospholipid signalling in plant defence. Curr. Opin. Plant Biol. 5, 332-338. doi: 10.1016/S1369-5266(02)00268-6

Liu, H., Hussain, S., Zheng, M., Peng, S., Huang, J., Cui, K., et al. (2015). Dry directseeded rice as an alternative to transplanted-flooded rice in Central China. Agron. Sustain. Dev. 35, 285-294. doi: 10.1007/s13593-014-0239-0

Manivannan, P., Jaleel, C. A., Kishorekumar, A., Sankar, B., Somasundaram, R., Sridharan, R., et al. (2007). Changes in antioxidant metabolism of Vigna unguiculata (L.) Walp. by propiconazole under water deficit stress. Colloids Surf. B Biointerfaces 57, 69-74. doi: 10.1016/j.colsurfb.2007.01.004

Mawlong, I., Ali, K., Srinivasan, R., Rai, R. D., and Tyagi, A. (2015). Functional validation of a drought-responsive AP2/ERF family transcription factorencoding gene from rice in Arabidopsis. Mol. Breed. 35, 163-176. doi: 10.1007/ s11032-015-0290-9

Mawlong, I., Kurup, D., Ali, K., Yadav, S., and Tyagi, A. (2014). Isolation and characterization of an AP2/ERF-type drought stress inducible transcription factor encoding gene from rice. J. Plant Biochem. Biotechnol. 23, 42-51. doi: 10.1007/s13562-012-0185-3

Mishra, S., Jha, A. B., and Dubey, R. S. (2011). Arsenite treatment induces oxidative stress, upregulates antioxidant system, and causes phytochelatin synthesis in rice seedlings. Protoplasma 248, 565-577. doi: 10.1007/s00709-010-0210-0

Møller, I. M., and Kristensen, B. K. (2004). Protein oxidation in plant mitochondria as a stress indicator. Photochem. Photobiol. Sci. 3, 730-735. doi: 10.1039/ B315561G

Nazarli, H., Ahmadi, A., and Hadian, J. (2014). Salicylic acid and methyl jasmonate enhance drought tolerance in chamomile plants. J. HerbMed Pharmacol. 3, 87-92.

Paparella, S., Arau, J. S. S., Rossi, G., Wijayasinghe, M., Carbonera, D., and Balestrazzi, A. (2015). Seed priming: state of the art and new perspectives. Plant Cell Rep. 34, 1281-1293. doi: 10.1007/s00299-015-1784-y

Pérez-Clemente, R. M., Vives, V., Zandalinas, S. I., López-Climent, M. F., Muñoz, V., and Gómez-Cadenas, A. (2012). Biotechnological approaches to study plant responses to stress. BioMed Res. Int. 13:e654120. doi: 10.1155/2013/ 654120

Pfaffl, M. W. (2001). A new mathematical model for relative quantification in real-time RT-PCR. Nucleic Acids Res. 29, e45. doi: 10.1093/nar/29.9.e45

Pill, W. G., and Gunter, J. A. (2001). Emergence and shoot growth of cosmos and marigold from paclobutrazol-treated seed. J. Environ. Hortic. 19, 11-14.

Ramegowda, V., and Senthil-Kumar, M. (2015). The interactive effects of simultaneous biotic and abiotic stresses on plants: mechanistic understanding from drought and pathogen combination. J. Plant Physiol. 176, 47-54. doi: 10.1016/j.jplph.2014.11.008

Ramirez, D. A., Monneveux, P., and Pino, M. T. (2015). Recent studies focussed on exploring the mechanisms of the priming effects and stress memory in the formation of drought tolerance in different plant species. Plant Sci. 9, 48-59.

Rao, S. P., Mishra, B., Gupta, S. R., and Rathore, A. (2013). Physiological response to salinity and alkalinity of rice genotypes of varying salt tolerance grown in field lysimeters. J. Stress Physiol. Biochem. 9, 54-65.

Salah, M., Yajing, G., and Jie, L. (2015). Seed priming with polyethylene glycol regulating the physiological and molecular mechanism in rice under nano- $\mathrm{ZnO}$ stress. Sci. Rep. 5:14278. doi: 10.1038/srep14278

Salzman, K., Bi, J. L., and Liu, T. X. (2005). Molecular strategies of plant defense and insect counter-defense. Insect Sci. 12, 3-15. doi: 10.4161/psb.24136

Sharma, P., Jha, A. B., Dubey, R. S., and Pessarakli, M. (2012). Reactive oxygen species, oxidative damage, and antioxidative defense mechanism in plants under stressful conditions. J. Bot. 2012:217037. doi: 10.1155/2012/217037
Singh, A., Bhushan, B., Gaikwad, K., Yadav, O. P., Kumar, S., and Rai, R. D. (2015). Induced defence responses of contrasting bread wheat genotypes under differential salt stress imposition. Ind. J. Biochem. Biophys. 52, 75-85.

Singh, B., and Usha, K. (2003). Salicylic acid induced physiological and biochemical changes in wheat seedlings under water stress. Plant Growth Regul. 39, 137-141. doi: 10.1023/A:1022556103536

Singleton, V. L., Orthofer, R., and Lamuela-Raventos, R. M. (1999). Analysis of total phenols and other oxidation substrates and antioxidants by means of Folin-Ciocalteu reagent. Methods Enzymol. 299, 152-178. doi: 10.1016/S00766879(99)99017-1

Soltys-Kalina, D., Plich, J., Strzelczyk-Zyta, D., Sliwka, J., and Marczewski, W. (2016). The effect of drought stress on the leaf relative water content and tuber yield of a half-sib family of 'Katahdin'-derived potato cultivars. Breed. Sci. 66, 328-331. doi: 10.1270/jsbbs.66.328

Tang, Y., Qin, S., Guo, Y., Chen, Y., Wu, P., Chen, Y., et al. (2016). Genomewide analysis of the AP2/ERF gene family in Physic Nut and over expression of the JcERF011 gene in rice increased its sensitivity to salinity stress. PLoS ONE 11:e0150879. doi: 10.1371/journal.pone.0150879

Trust, B., Shin, N., Jim, E. D., and Harry, D. S. (2005). Antioxidant activity of pearled wheat and roller milled fractions. Cereal Chem. 82, 390-393. doi: 10.1094/CC-82-0390

Varierf, A., Vari, A. K., and Dadlani, M. (2010). The subcellular basis of seed priming. Curr. Sci. 99, 450-456.

Wang, X., Li, Q., Yuan, W., Kumar, S., Li, Y., and Qian, W. (2016). The cytosolic Fe-S cluster assembly component MET18 is required for the full enzymatic activity of ROS1 in active DNA demethylation. Sci. Rep. 6:26443. doi: 10.1038/ srep26443

Wang, Z., Xu, Y., Chen, T., Zhang, H., Yang, J., and Zhang, J. (2015). Abscisic acid and the key enzymes and genes in sucrose-to-starch conversion in rice spikelets in response to soil drying during grain filling. Planta 241, 1091-1098. doi: 10.1007/s00425-015-2245-0

Wei, T., Deng, K., Gao, Y., Liu, Y., Yang, M., Zhang, L., et al. (2016). Arabidopsis DREB1B in transgenic Salvia miltiorrhiza increased tolerance to drought without stunting growth. Plant Physiol. Biochem. 104, 17-28. doi: 10.1016/j. plaphy.2016.03.003

Wu, H., Ye, H., Yao, R., Zhang, T., and Xiong, L. (2015). OsJAZ9 acts as a transcriptional regulator in jasmonate signalling and modulates salt stress tolerance in rice. Plant Sci. 232, 1-12. doi: 10.1016/j.plantsci.2014.12.010

Zhu, J.-K. (2002). Salt and drought stress signal transduction in plants. Annu. Rev. Plant Physiol. Plant Mol. Biol. 53, 247-273. doi: 10.1146/annurev.arplant.53. 091401.143329

Zhu, J.-K. (2016). Abiotic stress signaling and responses in plants. Cell 167, 313-324. doi: 10.1016/j.cell.2016.08.029

Conflict of Interest Statement: The authors declare that the research was conducted in the absence of any commercial or financial relationships that could be construed as a potential conflict of interest.

Copyright (@) 2017 Samota, Sasi, Awana, Yadav, Amitha Mithra, Tyagi, Kumar and Singh. This is an open-access article distributed under the terms of the Creative Commons Attribution License (CC BY). The use, distribution or reproduction in other forums is permitted, provided the original author(s) or licensor are credited and that the original publication in this journal is cited, in accordance with accepted academic practice. No use, distribution or reproduction is permitted which does not comply with these terms. 